\section{Re: A Reflective Case Study in Family Medicine Advance Care Planning Conversations}

To the Editor: Drs Tunzi and Ventres ${ }^{1}$ have addressed the importance of discussing advance care planning (ACP) with an integrative approach. ACP conversations should be broad yet flexible, and the surrogate's inclusion in the discussion is critical. It is appropriate for family physicians to initiate an ACP dialog considering their usually close relationship with the family.

From our experience, the discussion should not be initiated based on an individual reaching 65 years of age. An ACP should be considered for all adults, and the discussion best initiated during an annual physical. We proposed several steps for a meaningful dialog in an office setting. ${ }^{2}$ The physician should carefully prepare the ACP discussion: make it specific to the patient, allow adequate time, and even rehearse the methodology in approaching the issue. Emphasis should be placed on the fact that an advance directive (AD) is a legal document. It provides an individual's instructions regarding his/her future medical care and identifies the health care proxy agent. Furthermore, before the discussion, the physician should succinctly explain that ACP is a routine segment of an annual physical, and is relevant to adults of all ages.

Many factors may potentially arise during an ACP discussion. ${ }^{3}$ The physician may observe that the body language displayed demonstrates an uncomfortable attitude toward with the topic. Barriers are often raised ${ }^{4}$ that may be related to cultural, ${ }^{5}$ racial, ${ }^{6}$ religious, ${ }^{7}$ and/or gender issues. ${ }^{8}$ Medical procedures acceptable to the physician, may be unacceptable to the party involved. Some patients suffering a chronic illness and/or a terminal illness may nevertheless choose not to institute an AD. ${ }^{9}$ When a person refuses to enact an $\mathrm{AD}$, the physician must respect that decision.

A family member or a close trusted friend should be considered as the proxy agent and encouraged to attend a subsequent visit. The physician should emphasize that the surrogate is guided by the patient's wishes which are clearly detailed in the AD document. The surrogate will act as the proxy agent only when a patient is incapacitated and furthermore, it is the duty of the proxy agent to ensure that the individual's directives and wishes be fulfilled.

As mentioned previously, the physician's predialog preparation is vitally important for a successful discourse. The ACP discussion both educates and explores the benefits of an $\mathrm{AD}$, and further establishes that on signing the document, the individual can be confident that his/ her wishes will be respected and conducted in the future.

Pascal J. de Caprariis, MD, FAAFP Brooklyn, New York
To see this article online, please go to: http://jabfm.org/content/ 32/4/639. full.

\section{References}

1. Tunzi M, Ventres W. A reflective case study in family medicine advance care planning conversations. J Am Board Fam Med 2019;32:108-114.

2. de Caprariis PJ, Rucker B, Lyon C. Discussing advance care planning and directives in the general population. South Med J 2017;110:563-568.

3. Klugman CM. Advance directives to physicians: What every physician should know. South Med J 2012;105:289-291.

4. Spoelhof GD, Elliott B. Implementing advance directives in office practice. Am Fam Physician 2012;85:461-466.

5. Searight HR, Gafford J. Cultural diversity at the end of life: Issues and guidelines for family physicians. Am Fam Physician 2005;71:515-522.

6. Rhodes RL, Batchelor K, Lee SC, et al. Barriers to end-oflife care for African Americans from the providers' perspective: Opportunity for intervention development. Am J Hosp Palliat Care 2015;32:137-143.

7. Schmidt U. European Protestant churches reflect on endof-life issues. May 1, 2015. Available from: http://www. elca.org/JLE/Articles/1091. Accessed February 20, 2019.

8. de Caprariis PJ, Thompson S, Lippman N, et al. It is time for a gender specific discussion on advanced directives with female patients during routine health visits. J Community Health 2013;38:995-996.

9. de Caprariis PJ, Carballo-Diéguez A, Thompson S, et al. Advance directives and HIV: A current trend in the inner city. J Community Health, 2013;38:409-413.

doi: 10.3122/jabfm.2019.04.190065

The above letter was referred to the author of the article in question, who offers the following reply.

\section{Response: Re: A Reflective Case Study in Family Medicine Advance Care Planning Conversations}

To the Editor: We appreciate Dr. de Caprariis' thoughtful comments on our article. Indeed, we agree with nearly all them!

We do have 2 comments in return:

First, we suspect many practicing family physicians will find the suggestion of discussing Advance Care Planning (ACP) with all adults somewhat overwhelming. While we strongly encourage our colleagues to do that, we believe that targeting people over 65 years of age and patients of any age with serious acute or chronic illness is an alternative, pragmatic approach.

Second, although we absolutely support including ACP conversations as part of routine health care maintenance, we wonder about linking them to "annual physical" appointments. Many family physicians integrate preventive care longitudinally; the challenge, it seems to us, is to make the time to discuss document ACP some- 
time. Following up with undecided patients is also critical.

What is most important is that we family physicians integrate ACP with our patients, exploring what works best in context of our own practices.

Marc Tunzi, MD, MA

Natividad Medical Center, Salinas, California and the Department of Family and Community Medicine, University of California, San Francisco, San Francisco, CA

William Ventres, MD, MA Department of Family and Preventive Medicine, University of Arkansas for Medical Sciences, Little Rock, AR

doi: 10.3122/jabfm.2019.04.190110

To see this article online, please go to: http://jabfm.org/content/ 32/4/000.full.

\section{Re: Better Doctor-Patient Relationships Are Associated with Men Choosing More Active Depression Treatment}

To the Editor: I commend David Kealy and colleagues ${ }^{1}$ on their work on the doctor-patient relationship and men's choice of depression treatment. However, I do have a few concerns that would benefit from clarification.

First, the gender of the physician is an important covariate that should be accounted for in any doctorpatient relationship, as it affects this dynamic and its outcomes. $^{2}$ Roter and colleagues ${ }^{3}$ showed that female physicians engaged the patient in more positive conversation, gave more information, and built more partnership compared with the male physician; similarly, when patients are with female physicians, patients engage in more positive discussion and partnership building compared with male physicians. ${ }^{3}$ This article highlights men's choice regarding treatment and the relationship with their physician; controlling for the physician's gender could help improve the understanding of this doctorpatient relationship.

Second, the questionnaire implied that primary care doctors would administer the hypothetical treatment preference. Although I agree that primary care doctors often manage treatment-resistant depression, ${ }^{4}$ there exists a substantial section of the population that are referred to psychiatrists by primary care doctors. ${ }^{5}$ This article does not account for this population, especially given that attitudinal differences exist in managing depression and in terms of "professional ease in dealing with patients with depression" between general practitioners and psychiatrists. ${ }^{6}$ Thus, although the findings may apply to the primary care population, it excludes the treatment of depression in men managed by psychiatrists.

Ayodeji Otufowora, MBBS, MPH, CPH

Department of Epidemiology, College of Public Health and Health Professions and College of Medicine, University of Florida, Gainesville, FL, USA
To see this article online, please go to: bttp://jabfm.org/content/ 32/4/000.full.

\section{References}

1. Kealy D, Rice SM, Ferlatte O, Ogrodniczuk JS, Oliffe JL. Better doctor-patient relationships are associated with men choosing more active depression treatment. J Am Board Fam Med 2019;32:13-9.

2. Bertakis KD. The influence of gender on the doctor-patient interaction. Patient Educ Couns 2009;76:356-60.

3. Roter D, Lipkin M Jr., Korsgaard A. Sex differences in patients' and physicians' communication during primary care medical visits. Med Care. 1991;29:1083-93.

4. Schwenk TL, Evans DL, Laden SK, Lewis L. Treatment outcome and physician-patient communication in primary care patients with chronic, recurrent depression. Am J Psychiatry 2004;161:1892-901.

5. Peterson BD, Pincus HA, Suarez A, Zarin DA. Datapoints: referrals to psychiatrists. Psychiatr Serv 1998;49:449-449.

6. Kerr M, Blizard R, Mann A. General practitioners and psychiatrists: comparison of attitudes to depression using the depression attitude questionnaire. Br J Gen Pract 1995; 45:89-92.

doi: 10.3122/jabfm.2019.04.190079

The above letter was referred to the author of the article in question, who offers the following reply.

\section{Response: Re: Better Doctor-Patient Relationships Are Associated with Men Choosing More Active Depression Treatment}

To the Editor: We thank Dr. Otufowora for commenting on our work regarding the doctor-patient relationship and men's choice of depression treatment ${ }^{1}$ and for raising concerns about the potential role of the physician's gender and the specialist status of the treatment provider.

Rather than address the abovementioned questions, our study focused on men's overall experience of the quality of their relationship with their family physician. Although female physicians may be perceived as more caring with regard to depression management, ${ }^{2}$ some research suggests complex interactions between patient and physician gender and whether the physician adopts a patient-centered orientation. ${ }^{3}$ Thus, although gender matters, the nature of the doctor-patient communication is also important. We suspect similar interactions regarding the treatment contextwhether primary care physician or mental health specialist-in that the quality of the relationship would remain influential. Indeed, research has shown considerable "provider effects" among psychiatrists, with some achieving superior outcomes prescribing placebo to others prescribing antidepressants. ${ }^{4}$

Considering the risks for suicide and atypical depression presentations among men, ${ }^{5}$ a better understanding of men's treatment engagement-including 